\title{
A Discussion of Magnetoelectric Composite Design by Bonding the Ferromagnetic Material Graded Layers in Induction Motor
}

\author{
Zuriman Anthony ${ }^{1,2 *}$, Hairul Abral ${ }^{3}$, Refdinal Nazir ${ }^{4}$ \\ ${ }^{1}$ Program Doctoral Student of Andalas University, Indonesia, Mechanical Engineering Department \\ ${ }^{2}$ Institute of Technology Padang (Institut Teknologi Padang), Indonesia, Electrical Engineering Department \\ ${ }^{3}$ Andalas University, Indonesia, Mechanical Engineering Department \\ ${ }^{4}$ Andalas University, Indonesia, Electrical Engineering Department
}

\begin{abstract}
Induction motors are the most electric motors widely used in the community, both in the industrial and in the household applications. The power and efficiency of the motors are determined by the type of ferromagnetic material used in the core of the motor. If a very good ferromagnetic material with high permeability is applied to the core of the induction motor, then both the energy conversion and the efficiency of the motor will increase. But, if the ferromagnetic material is not good with low permeability is used in the induction motor, of course, the conversion of energy generated by the motor will be low so that the motor efficiency becomes decreased. In other cases, when ferromagnetic materials with high permeability are used, these ferromagnetic materials will become more fragile than using ferromagnetic materials with lower permeability. Therefore, a good strategy is needed in designing the core material of the induction motor. This study was intended to provide an overview of the potential use of a composite material of $\mathrm{Fe}$ and ferromagnetic material that was made in the Graded Magnetostrictive Layers. This research was conducted using several studies of the results of research on the composite material of the magnet. The results of the study show that a composite material of $\mathrm{Fe}$ and ferromagnetic materials provided a great potential in applying to induction motors to increase power and efficiency of the motor.
\end{abstract}

\section{Introduction}

Induction motors are electric motors of alternating current which are widely used both in the industrial sector and in the household sector [1]. The efficiency of the motors are strongly influenced by the type of ferromagnetic material used in the motors, the air gap distance between the stator and the rotor, the shape of the rotor, and the type of material and number of coil windings used on the motor [1-4]. Some methods had been developed to improve performance of the motor by operating the motor on single-phase supply. The methods can improve power factor, starting torque and efficiency of the motor $[5,6]$. Some research had developed to analyze the motor by using equivalent circuit to improve performance of the motor [7-9].

Ferromagnetic material is the main material in the induction motor which is very useful in strengthening the magnetic field of the motor resulting great torque and efficiency in the motor [1]. The performance of these ferromagnetic materials is strongly influenced by the permeability, currents, and the internal and external influences of materials $[1,10]$. One of the external influences affecting the ferromagnetic materials is the heat that arises in the process of cutting ferromagnetic material either by mechanically or laser, and the effect of welding materials that can decrease the properties of ferromagnetic material $[11,12]$. In addition, the decrease of the ferromagnetic material properties may also be caused by the influence of heat originating from within the stator core as a result of the magnetization of the stator and from the influence of the surrounding heat as a result of rotor heat induction to the stator $[1,3,10,13]$. The heat that occurs in this motor (both from the stator and the rotor) can increase the power loss and decrease the performance and efficiency of the motor [1,2].

To analyze the characteristic of ferromagnetic materials, several studies have been undertaken by previous researchers by developing modeling and use approach formulas for analyzing the properties of ferromagnetic materials. Such as those used to predict thermal transient behavior due to heating process [3], the effect of cutting materials [12], the magnetic field and iron core losses on the rotor [14], and to find out the magnetic properties of the material that can be used in the practical evaluation of simpler hysteresis effects [15]. From the results of analyzes that have been done through these studies, it turns out the heat that occurs in this ferromagnetic material can reduce the magnetic properties or the quality of ferromagnetic materials.

\footnotetext{
* Corresponding author: antoslah@gmail.com
} 
To minimize the effect of heat on ferromagnetic material of the induction motor can be done by choosing more precise ferromagnetic cutting technique $[11,12]$, to design optimally the shape of the rotor slot [16] and the use of copper material on the rotor winding rather than the aluminum [3]. However, the use of copper materials would require a more expensive cost than the aluminum material.

Improvements in the properties of ferromagnetic materials can also be done by coating (laminated composite) ferromagnetic materials that are less good but strong physically with excellent ferromagnetic materials so that this excellent material that has a dominant effect [17] or by the use of magnetic fluids based on heat-synthesized synthesized nanoparticles [13] which has been used for electronic devices. Improved motor efficiency by improving the properties of this ferromagnetic material can also be done by using an amorphous laminate material at the core of the stator [18], soft magnetic composites (SMC) on the stator [2], and the use of magnetic wedge in the stator coil slot to reduce air passage flux distortion, magnetization currents, start current and temperature rise $[19,20]$.

Besides that, the magnetic properties of demagnetization can be overcome by increasing the number of pole magnetic of stator and the use of a permanent magnetic ferrite material on the rotor surface, as has been applied to permanent magnetic synchronous motors [21]. However, increasing the number of pole magnetic stator is not possible to be applied to the induction motor because will decrease the speed of the motor. Therefore, we need a new method that is simple and cheaper to be applied to the induction motor in an effort to improve motor performance.

\section{Research Method}

This paper describes the results of a review of several journals that become reverence with the topic of study leads to an effort in improving the performance of induction motors in focusing on ferromagnetic materials on the motor. A simple method is offered to improve motor performancey. motor

\section{Results and Discussion}

With reference to the results of research conducted by several studies of before, it can be described some of the following studies.

From the result of [22], there were 4 resins used to obtain the materials composites of the stator. They are HRJ10236 (RA), SBP-128 (RB), SP6600 (RC) and SP6601
(RD) with mass proportions of $0.5 \%, 1.0 \%, 1.5 \%, 2.0 \%$, $2.5 \%$ and $3.0 \%$. The specifications and the magnetic properties of the composites are shown in table 1 and table 2 respectively.

Table 1. Resin Specifications [22]

\begin{tabular}{lllll}
\hline Specifications & HRJ-10236 & SBP-128 & SP6600 & SP6601 \\
\hline Curing at $154^{\circ} \mathrm{C}$ & $50-90 \mathrm{~s}$ & $30-65 \mathrm{~s}$ & $15-30 \mathrm{~s}$ & $15-30 \mathrm{~s}$ \\
Density $\left(\mathrm{g} / \mathrm{cm}^{3}\right)$ & 0.350 & 0.355 & 0.352 & 0.334 \\
Hexamine content (\%) & $7.5-8.5$ & $8.5-9.5$ & $6.9-7.9$ & $6.5-8.5$ \\
Granulometry (M\# 200) & min. 97\% & min. 97\% & min. 97\% & min. 99.9\% \\
\hline
\end{tabular}

Table 2. Specifications of magnetic properties for the composites [22].

\begin{tabular}{|c|c|c|c|}
\hline Composite & $\frac{\mathrm{B}_{\max }}{[\mathrm{T}]}$ & $\frac{\mathrm{B}_{\mathrm{f}}}{[\mathrm{T}]}$ & $\frac{\mathrm{H}_{\mathrm{c}}}{[\mathrm{A} / \mathrm{m}]}$ \\
\hline Fe-RA0.5 & 0.64 & 0.10 & 272 \\
\hline Fe-RA3.0 & 0.45 & 0.04 & 223 \\
\hline Fe-RB0.5 & 0.61 & 0.10 & 261 \\
\hline Fe-RB3.0 & 0.45 & 0.04 & 255 \\
\hline Fe-RC0.5 & 0.63 & 0.11 & 280 \\
\hline Fe-RC3.0 & 0.43 & 0.05 & 271 \\
\hline Fe-RD0.5 & 0.58 & 0.11 & 260 \\
\hline Fe-RD3.0 & 0.42 & 0.04 & 243 \\
\hline
\end{tabular}

Table 2 shows that the less resin content (Fe-RA0,5) or in other words, the higher the $\mathrm{Fe}$ percentage in the composite, the maximum magnetic flux density (Bmax) will be greater. This means that the higher Fe content will strengthen the maximum magnetic flux density of soft magnetic composite material.

From the result of [23], also show the same characteristic with [22], although in deference case. This paper [23] had researched used three kinds different average particle size of iron powders $(140,107$ and 75 $\mu \mathrm{m})$. They are shown in Fig. 1, Fig. 2 and Fig. 3.
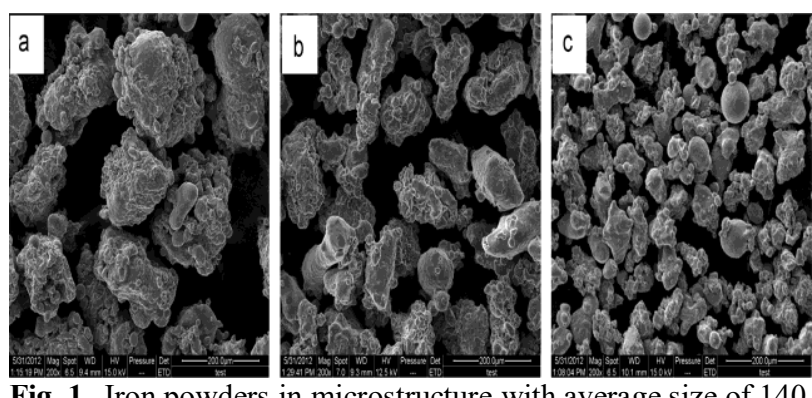

Fig. 1. Iron powders in microstructure with average size of 140 $\mu \mathrm{m}$ (a), $107 \mu \mathrm{m}$ (b) and $75 \mu \mathrm{m}$ (c) respectively [23]. 

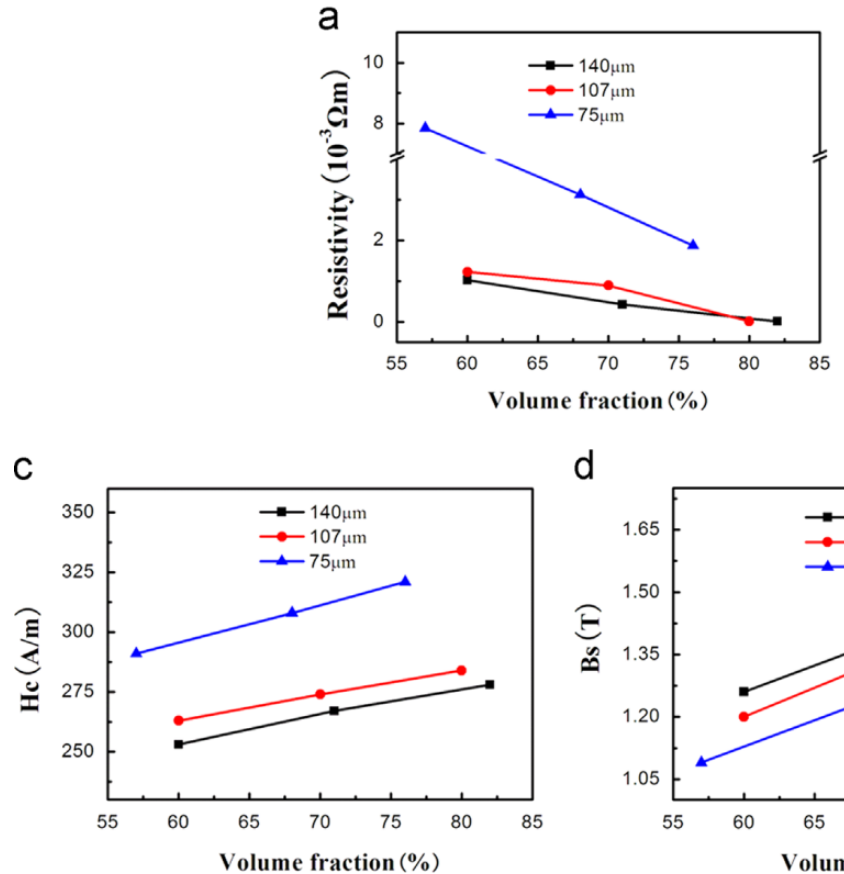

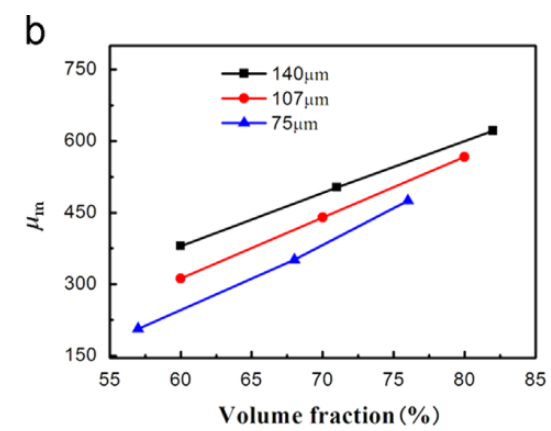

d

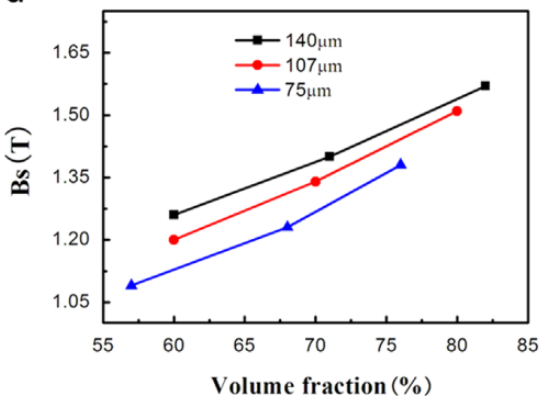

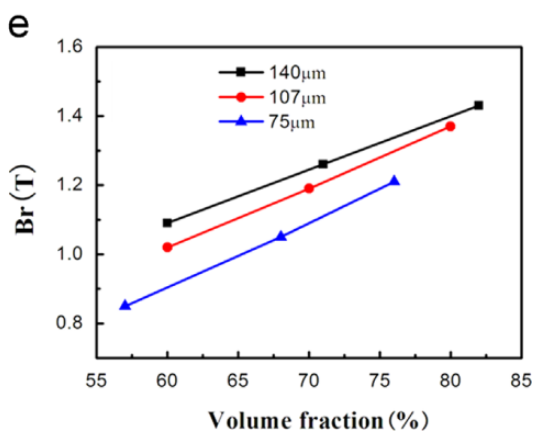

Fig. 2. Relationship of resistivity (a), maximum relative permeability (b), coercivity (c), saturation magnetic flux density (d) and residual magnetic flux density (e) of $\mathrm{Fe} /$ silicate glass composites with iron particle volume fraction respectively [23].

a

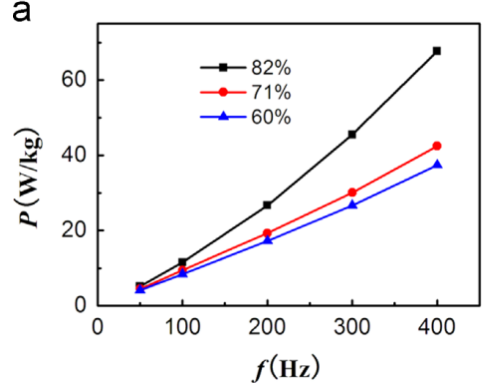

b

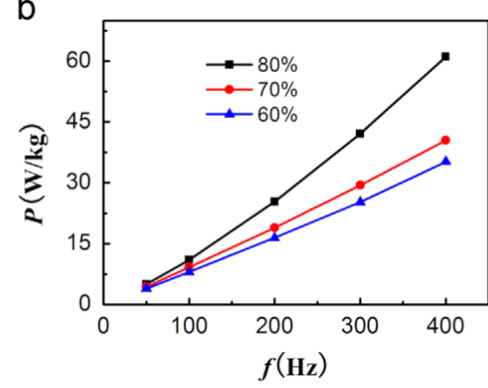

C

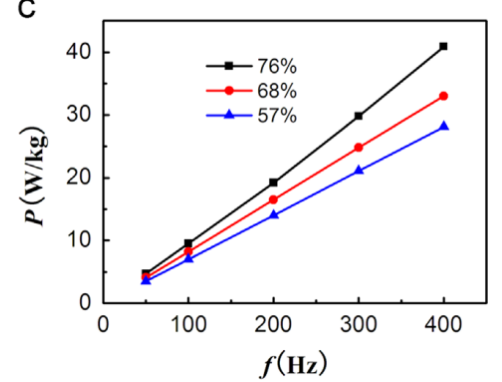

Fig. 3. Relationship of core loss (W) versus frequency (f) of some Fe/silicate glass composites with average size of $140 \mu \mathrm{m}$ (a), 107 $\mu \mathrm{m}(\mathrm{b})$ and $75 \mu \mathrm{m}$ (c) respectively at the induction level of $1 \mathrm{~T}[23]$.

From Fig. 2 it is seen that the magnetic flux density (Bs and $\mathrm{Br}$ ) will increase when the Fe content in the compound material is to increase as shown in Figures (2d) and (2e). On the contrary, as more silicate mixture will reduce the core loss as shown in Fig. 3.

From both results above it can be seen that increasing the $\mathrm{Fe}$ content in the compound material will enlarge magnetic flux density ( $\mathrm{Bs}$ and $\mathrm{Br}$ ). With the greater the magnetic flux density (Bs and $\mathrm{Br}$ ) the greater the energy that can be transferred from the stator to the rotor that effect for improving the capability of the motor. On the other hand, adding a mixture of insulating / silicate to the material will minimize losses in the core. Therefore, the stator core design of the induction motor is recommended by using a multilayered core material such as a transformer core, by means of a core layer made of a fine ferromagnetic layer and combined with an iron $(\mathrm{Fe})$ layer so that the core construction of the material is expected to be cheaper with better energy conversion. Research with this method is in the process of further action as a study.

\section{Conclusions and Recommendations}

From the results of the above-described study it is concluded that it is possible to construct an induction motor with the stator by using a multilayered core material such as a transformer core, by means of a core layer made of a fine ferromagnetic layer and combined with an iron (Fe) layer so that the core construction of the material is expected to be cheaper with better energy conversion. Research with this method is in the process of further action as a study.

\section{References}

1. P. C. Sen, Principles of Electrical Machines and Power Electronics. (John Wiley \& Sons, 1996).

2. A. Krings, et al. Characteristics comparison and selection guide for magnetic materials used in 
electrical machines. 2015 IEEE Int. Electr. Mach. Drives Conf. 1152-1157 (2015). doi:10.1109/IEMDC.2015.7409206

3. F. Ahmed, E. Ghosh, N. C. Kar, Transient Thermal Analysis of a Copper Rotor Induction Motor using a Lumped Parameter Temperature Network Model. IEEE (2016).

4. I. Boldea, Electric Generators and Motors: An Overwiew. CES Trans. Electr. Mach. Syst. IEEE 1, 12 (2017).

5. Z. Anthony, A Simple Method for Operating the Delta Connection Standard of the 3-phase Induction Motor on Single Phase Supply. IJETT 15, 444-447 (2014).

6. Z. Anthony, A Simple Method For Operating The Three-Phase Induction Motor On Single Phase Supply ( For Wye Connection Standard ). IJETT 5, 13-16 (2013).

7. Z. Anthony, Equivalent Circuits for the M31DZA Motor "s Method ( Case Studies: Currents and Power Factor of the motor ). IJETT 25, 49-52 (2015).

8. Z. Anthony, E. Erhaneli, B. Busran, A NEW EQUIVALENT CIRCUIT OF THE THREEPHASE INDUCTION MOTOR ( CASE STUDIES : CURRENT AND POWER FACTOR OF THE MOTOR ). 12, 6967-6974 (2017).

9. Z. Anthony, E. Erhaneli, B. Busran, A New Method for Analyzing the Characteristics of The 3-Phase Induction Motor. in International Conference on Technology, Innovation, and Society (ICTIS) 2017 145-151 (ITP Press, 2016). doi:10.21063/ICTIS.2016.121

10. H. S. Ju, et al., Efficient Deperming Protocols Based on the Magnetic Properties in Demagnetization Process. IEEE Trans. Magn. 51, (2015).

11. P. Rasilo, U. Aydin, T. P. Holopainen, A. Arkkio, Analysis of iron losses on the cutting edges of induction motor core laminations. Proc. - 2016 22nd Int. Conf. Electr. Mach. ICEM 20161312 1317 doi:10.1109/ICELMACH.2016.7732694

(2016).

12. K. Bourchas, et al., Influence of cutting and welding on magnetic properties of electrical steels. 2016 XXII Int. Conf. Electr. Mach. 18151821

doi:10.1109/ICELMACH.2016.7732770

(2016).

13. Y. Shlapa, S. Solopan, A. Belous, Effect of Mechano-Chemical Processing in the Synthesis of Weakly Agglomerated Ferromagnetic La 1-x Sr x $\mathrm{MnO} 3$ Nanoparticles on their Properties. IEEE 282-286 (2015).

14. Z. Haisen, Z. Dongdong, W. Yilong, Z. Yang, X. Guorui, Piecewise Variable Parameter Loss Model of Laminated Steel and its Application in Fine Analysis of Iron loss of Inverter-Fed Induction Motors. IEEE 1-8 (2016).

15. D. Herceg, D. Herceg, M. Prsa, Using Padé Approximation in Takács Hysteresis Model. IEEE Trans. Magn. 51, 1-5 (2015).

16. S. Sobhani, H. Yaghobi, M. Samakoosh, Optimize efficiency and torque in the single-phase induction motor by adjusting the design parameters. 12th Int. Conf. Environ. Electr. Eng. EEEIC $2013 \quad 237-241 \quad$ (2013). doi:10.1109/EEEIC.2013.6549623

17. C. Yang, et al., Large Converse Magnetoelectric Properties Without Bias in Composite of RosenType Piezoelectric Transformer and Magnetization-Graded Ferromagnetic Material. IEEE Trans. Magn. 51, 8-11 (2015).

18. M. Dems, K. Komeza, Performance Characteristics of a High-Speed Energy-Saving Induction Motor with an Amorphous Stator Core. IEEE Trans. Ind. Electron. 61, 3046-3055 (2014).

19. T. R. Gaerke, D. C. Hernandez, The temperature impact of magnetic wedges on TEFC induction motors. IEEE Trans. Ind. Appl. 49, 1228-1233 (2013).

20. M. Lavanya, P. Selvakumar, D. S.Vijayshangkar, D. C. Easwarlal, Performance analysis of three phase induction motor using different magnetic slot wedges. IEEE 164-167 (2014).

21. I. Petrov, M. Niemela, P. Ponomarev, J. Pyrhonen, Rotor Surface Ferrite Permanent Magnets in Electrical Machines: Advantages and Limitations. IEEE Trans. Ind. Electron. 64, 5314 5322 (2017).

22. M. M. Dias, et al., Influence of resin type and content on electrical and magnetic properties of soft magnetic composites (SMCs). Powder Technol. 237, 213-220 (2013).

23. W. Ding, et al., Effect of iron particle size and volume fraction on the magnetic properties of $\mathrm{Fe} /$ silicate glass soft magnetic composites. $J$. Magn. Magn. Mater. 378, 232-238 (2015). 